\title{
Communication
}

\section{An Exploration of Online Teaching in Diagnostics Under COVID-19}

\author{
Hong Chen ${ }^{1}$, Xueqiang Xu ${ }^{1}$, Anqi Yang ${ }^{2}$, Yan Yang ${ }^{1}$, Liling Chen ${ }^{2, ~ * ~}$ \\ ${ }^{1}$ The Department of Diagnostics of The First school of Clinical Medicine, Nanjing Medical University, Nanjing, China \\ ${ }^{2}$ The Academic Affairs Office of The First school of Clinical Medicine, Nanjing Medical University, Nanjing, China
}

\author{
Email address: \\ cll@njmu.edu.cn (Liling Chen) \\ ${ }^{*}$ Corresponding author
}

\section{To cite this article:}

Hong Chen, Xueqiang Xu, Anqi Yang, Yan Yang, Liling Chen. An Exploration of Online Teaching in Diagnostics Under COVID-19. Higher Education Research. Vol. 5, No. 6, 2020, pp. 214-221. doi: 10.11648/j.her.20200506.12

Received: November 4, 2020; Accepted: November 16, 2020; Published: November 27, 2020

\begin{abstract}
This paper introduces that the department of the Diagnostics of The First School of Clinical Medicine at Nanjing Medical University use network information technology to conduct online teaching during the novel coronavirus epidemic. Objectives: To share the experience of comprehensive online teaching, and to investigate students' use of Fanya. Chaoxing online learning during the Diagnostics course under the COVID-19. Methods: We randomly selected Diagnostics as the course which we investigated and analyzed through using questionnaires. Results: $94.24 \%$ of students use smart phones to study online. $86 \%$ of students spend 1-6 hours per week studying Diagnostics. $79 \%$ of students have access to obtain the majority of online teaching resources. $86.3 \%$ of students expressed that they could achieve the learning objectives and meet the learning requirements of online learning content. The fluency score for watching instructional videos reached $87.13 \% .92 \%$ of students believed course materials were helpful to them. There were many difficulties such as unclear assessment method, overwhelmed and unable to maintain learning progress, lack of learning resources. Conclusions: Chinese network can basically meet the needs of comprehensive online teaching. The materials for online teaching can basically meet the needs of teaching. Making a clear assessment method timely, assigning appropriate homework and preparing the learning materials as more as possible are necessary. Organizing student learning at different times and supporting by the National Information Network Department are important.
\end{abstract}

Keywords: COVID-19, Online Teaching, Teaching Form, Diagnostics

\section{Introduction}

Since December 2019, the COVID-19 outbreak has gradually spread in China and throughout the world [1, 2]. Chinese primary and secondary school students were facing the end of their winter vacation, in order to prevent the continued spread of COVID-19, on February 4, 2020, the Chinese Ministry of Education issued a guidance document stating that while they would "postpone the reopening of schools" [3]. "Classes [would] not be suspended" [4]. Nanjing Medical University immediately launched an online teaching program. In recent years, as software and hardware environments and smartphones have developed, The First School of Clinical Medicine has accumulated a large amount of modern teaching resources. To meet the major challenges in comprehensive online teaching, the Academic Affairs Office of The First School of Clinical Medicine has put forth tremendous effort. In this paper, we share The First School of Clinical Medicine of Nanjing Medical University's online teaching experiences under COVID-19 and analyze the Diagnostics course's online teaching results.

Online courses have proliferated in Chinese universities in recent years, including constructing an E-learning environment [5]. Using a Microlecture method [6], and using MOOC (Massive Open Online Courses) [7]. Among other platforms. These courses typically complement or act as icing on the cake to a traditional class. This perception may be related to the immature management and evaluation 
mechanism for purely online teaching. Therefore, most Chinese classes up to this point still use traditional offline teaching.

Simultaneously, the National Education Ministry transformed university teaching concepts. It launched a selection of national "golden courses", which vigorously developed online teaching, established student-centered learning, put an end to simply transferring knowledge at the expense of cultivating ability and quality, and improved the formative assessment system [8]. Traditional Chinese culture has influenced Chinese college offline classes for centuries. The teaching method has primarily been didactic - teachers talk and students listen. As a result, students cannot develop self-learning abilities effectively, educational efficiency is not high, and creative talents cultivated by the state are lacking [9].

Therefore, comprehensive online teaching under the COVID-19 outbreak is a double-edged sword, which is not only a great challenge for all the courses but is also an excellent opportunity for curriculum development.

\section{Methods}

\subsection{Work Procedure and Implementation Steps}

\subsubsection{Division of Labor}

First, the college rapidly established an online teaching work group, which the college dean leads. The leader of the department of Diagnostics is responsible for online teaching quality assurance, clinical teachers are responsible for online teaching, and the Academic Affairs Office is responsible for guiding teachers in online teaching, tracking teaching activity, and collecting and analyzing feedback from teachers and students.

\subsubsection{Survey of Student Learning Conditions}

Due to a great number and wide distribution of students, the devices used and network configurations on the student side are important factors influencing the effects of online teaching. The college, therefore, conducted a questionnaire that mainly concentrated on the following questions: Was a computer available? What type of computer operating system did it have? Was it only a mobile phone? Was there WIFI at home? Was there broadband? Was there Mobile Traffic? Was the Mobile Traffic sufficient? According to the data analyzed using the questionnaire, all students have smartphones that essentially meet the software and hardware requirements for online learning. Some economically disadvantaged students must use mobile internet data because they do not have WIFI at home. In these cases, the college subsidizes communication fees.

\subsubsection{Teaching Tools}

The teaching tool is mainly based on the Fanya. Chaoxing (http://fanya.chaoxing.com/portal) network teaching platform. It includes a PC and mobile app. PowerPoint (PPT).

\subsubsection{Teaching Content}

The college sends Guidelines for the Prevention and
Control of Coronavirus to each student electronically [10]. Because a portion of clinical teachers moved to the front lines of the epidemic area (with a spirit of devotion that moved the whole country), the Ministry of Education also organized a gathering of national college students to attend a live class on ideology and politics related to epidemic prevention and control [11]. Since The First School of Clinical Medicine is a medical university, the Academic Affairs Office requires the course to include medical humanities and professional ethics.

\subsubsection{Specific Teaching Methods}

\section{i. Teaching format}

After discussion and analysis by college network technicians, the college decided not to use live broadcast lectures. First, all Chinese schools are using online teaching, creating a huge risk for network congestion. Second, live broadcasts require highly skilled computing capabilities. General online teaching platforms would suffer from various slowdowns, which would affect lecture quality, making it difficult to monitor and control live broadcast content. For these reasons, we decided on producing a class recording offered with a PPT. Alongside these items, we set up a playback feature and an online question-and-answer model. To organize our teaching methods, we chose online teaching platform Fanya. Chaoxing owned by one of the largest companies devoting to education in China.

ii. Frame structure

First, the Academic Affairs Office staff used chatting softwares to train the course's teaching secretary to download and use the Fanya. Chaoxing network teaching platform. Next, the course leader established a course on Fanya. Chaoxing, published the course introduction, published learning objectives, published assessment requirements, formulated a specific study plan, and imported student information.

And the teaching task included theoretical and practical lessons. For theoretical lessons, critically, clinical teachers used PPT's screen recording function to record explanations. Finally, videos were made to substitute for not having traditional face-to-face teaching.

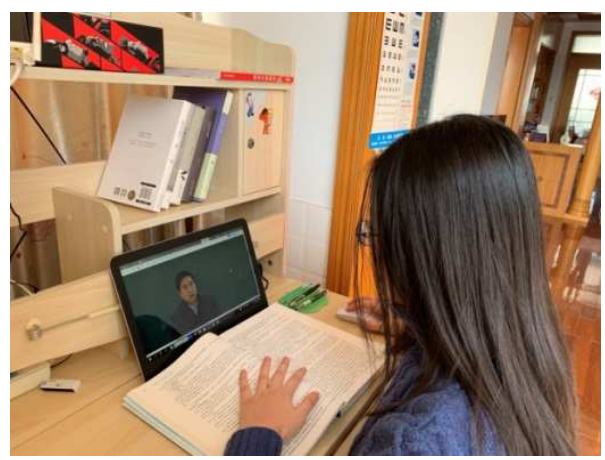

Figure 1. Student learning via a PPT course video recording at home.

Teachers uploaded the PPT course recording, audio and video materials, e-textbook, outline, preview requirements, and other content during their normal teaching schedules. During their original course times, online classes begin. The 
teacher turns on "sign in", and the students access all of the course materials. Additionally, the teacher answers questions and interacts with students on message board system after class. Last, the teacher assigns homework, checks students'

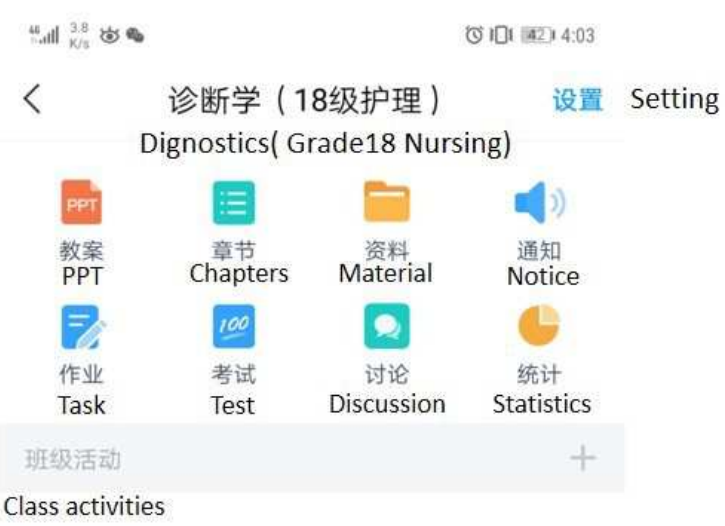

mastery and gives evaluations. An example of a student learning online via a PPT course with a recorded video at home is shown in Figure 1, and the Fanya. Chaoxing network teaching platform app interface is shown in Figure 2.

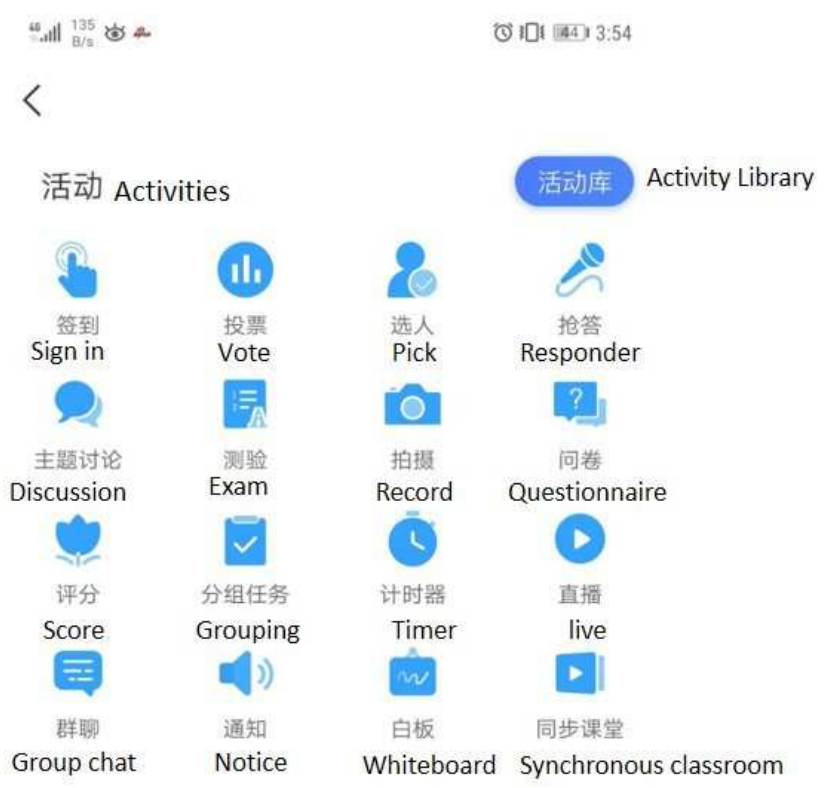

Figure 2. Fanya Chaoxing network teaching platform app learning interface.

For practical lessons, teachers required students to learn standardized videos of physical examination first, and then submit operation video at home cooperated with their family members as SPs (Standardized Patients). Learning interface of standard physical examination videos on Fanya. Chaoxing

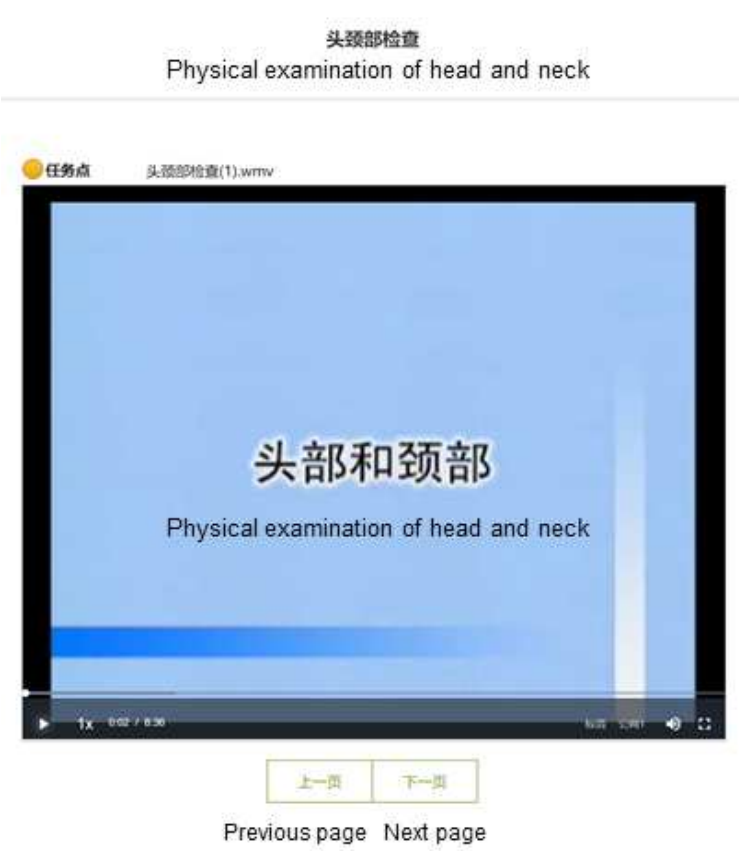

network teaching platform app is shown in Figure 3, and an example of a student's video homework with family SP for performing physical examination of thyroid is shown in Figure 4.

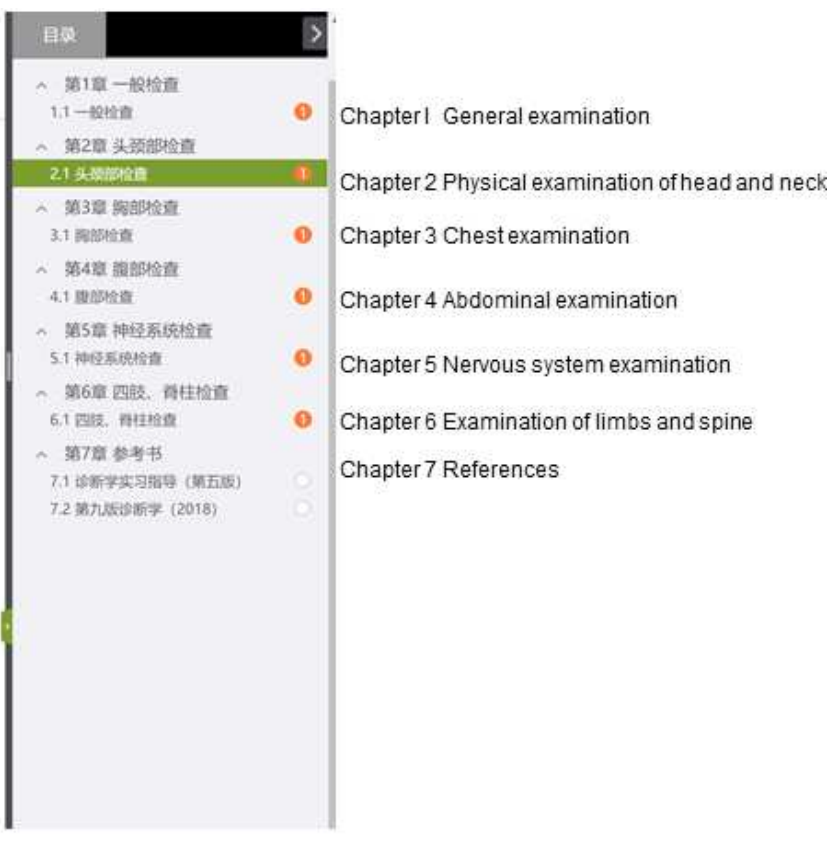

Figure 3. Learning interface of standard physical examination videos. 


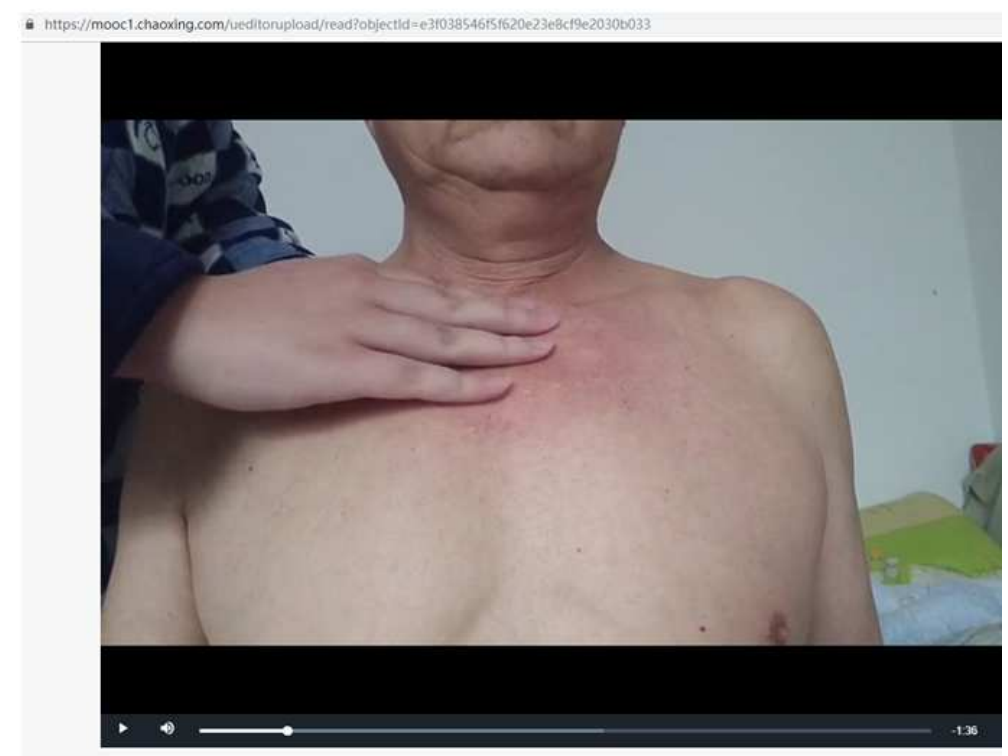

Figure 4. Physical examination of thyroid-Students' video homework with family SP.

iii. Feedback

Based on students' homework and test results, the teacher can assess students' understanding of the course's learning objectives. The teacher then gives overall feedback, using the software's discussion function. In addition, students have the option to ask their teacher questions on the message board system or chatting with teachers by the APP. An example of the teacher's comment for the video homework is shown in Figure 5, and the students' messages on message board system is shown in Figure 6.

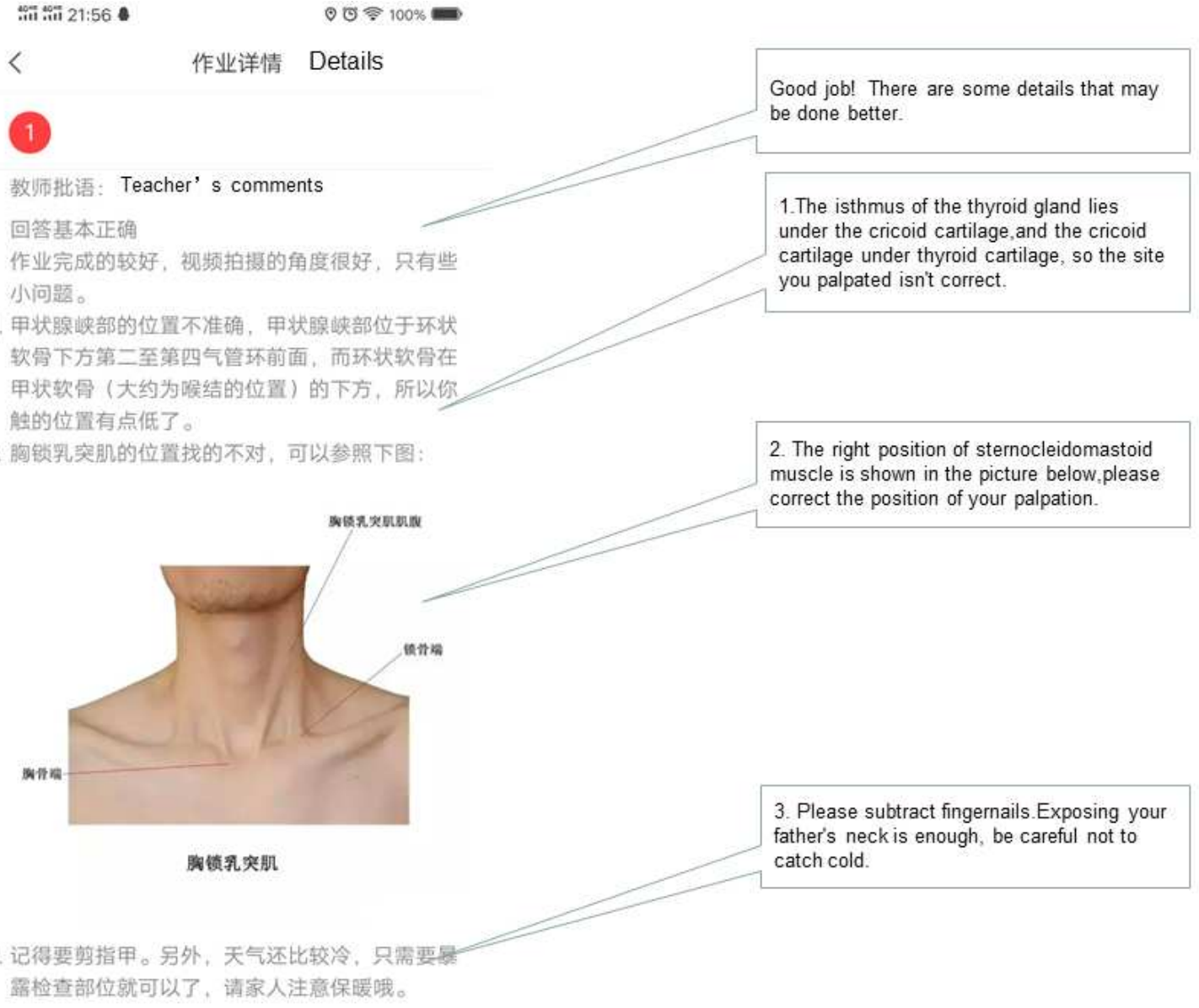

Figure 5. Interface of comments by teachers. 


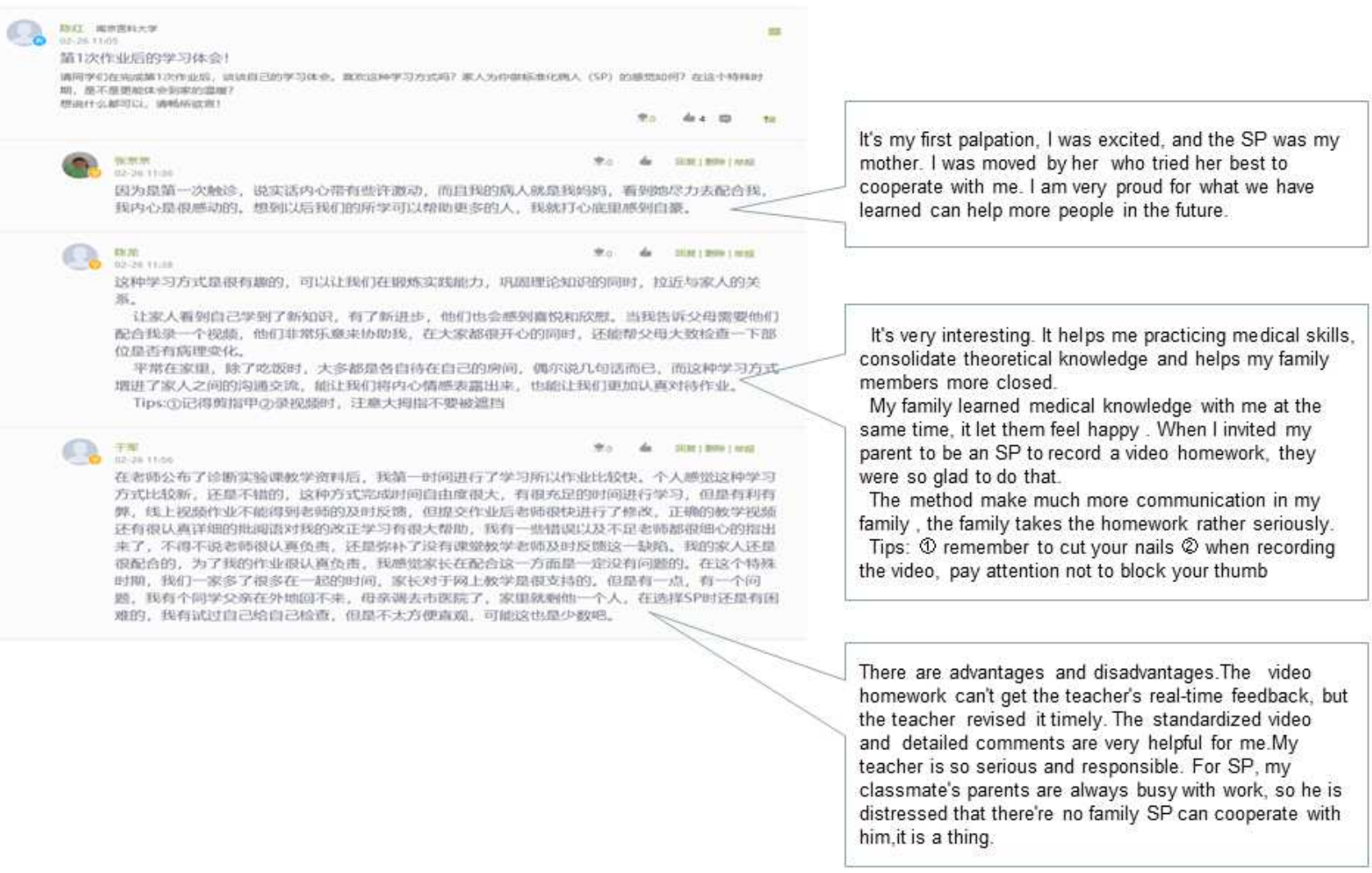

Figure 6. Students' messages on the message board system.

\subsection{Questionnaire}

After 4 weeks of online teaching, to understand the development of comprehensive online teaching, the Academic Affairs Office assessed student performance in the Diagnostics course and randomly investigated class of 2018 nursing students. The Fanya. Chaoxing network teaching platform app's statistical function showed that class of 2018 nursing students' visits to the network reached a total of 10,443 in the 4 weeks, averaging a daily amount of 1.7 visits. The per-percent completion rate of teaching materials browsed was $85 \%$, the total completion rate of 4 assignments was $91.5 \%$, and the 4 assignments averaged a score of $87.5 \pm 5.3$ points (out of 100 points), which was normally distributed.

Survey participants: 219 Grade 3 nursing students.

Survey purpose: To investigate students' use of Fanya. Chaoxing online learning during the Diagnostics course.

Survey content: Identifying online learning devices students used, quantifying time spent studying, assessing whether students can obtain teaching resources online, noting how fluently students browse teaching resources online, viewing how students evaluate teaching resource effectiveness, finding the rate of learning target acquisition, and identifying existing problems in online teaching.

Survey method: Questionnaire through Questionnaire Star survey software, which issued a two-dimensional code to 219 nursing students. The software automatically recovered 219 copies, which achieved a recovery rate of $100 \%$.

\section{Results}

Devices students use for online learning are shown in Table 1. Results showed that $94.24 \%$ of students use smart phones to study online, $50.68 \%$ of students use computers, and $20.09 \%$ of students use PAD.

Table 1. Devices students use for online learning.

\begin{tabular}{llll}
\hline Items (Multiple Choice) & Subtotal & Ratio & \\
\hline Computer & 111 & $50.68 \%$ \\
Smart phone & 202 & $92.24 \%$ \\
PAD & 44 & $20.09 \%$ \\
Total & 219 & \\
\hline
\end{tabular}

Results showed that $86 \%$ of students spend 1-6 hours per week studying Diagnostics, very few spend less than 1 hour, and $11 \%$ of students study more than 6 hours. 
Table 2. The average time students spent studying online each week.

\begin{tabular}{llll}
\hline Items (Single Choice) & Subtotal & Ratio & \\
\hline Less than 1 hour & 7 & $3.2 \%$ \\
1-3 hours & 94 & $42.92 \%$ \\
3-6 hours & 94 & $42.92 \%$ \\
More than 6 hours & 24 & $10.96 \%$ \\
Total & 219 & \\
\hline
\end{tabular}

Results show that students have access to the majority of online teaching resources.

Table 3. Student capacity to obtain the syllabus, teaching materials, reference books, PPT and teaching videos in a timely manner.

\begin{tabular}{|c|c|c|}
\hline Items (Single Choice) & Subtotal & Ratio \\
\hline All materials & 33 & $15.07 \%$ \\
\hline Most materials & 173 & $79 \%$ \\
\hline Few materials & 13 & $5.94 \%$ \\
\hline No materials & 0 & $0 \%$ \\
\hline Total & 219 & \\
\hline
\end{tabular}

$86.3 \%$ of students expressed that they could achieve the learning objectives and meet the learning requirements of online learning content.

Table 4. Student capacity to meet the set of online learning objectives and requirements.

\begin{tabular}{llll}
\hline Items (Single Choice) & Subtotal & Ratio & \\
\hline YES & 189 & & $86.3 \%$ \\
NO & 30 & $13.7 \%$ \\
Total & 219 & & \\
\hline
\end{tabular}

The survey shows that the fluency score for watching instructional videos reached $87.13 \%$, browsing PPT was $86.83 \%$, and reading other text documents was $81.9 \%$.

Table 5. Fluency scores for watching instructional videos, browsing PPT, and reading other text materials.

\begin{tabular}{ll}
\hline Items & The average score (totally $\mathbf{1 0 0}$ points) \\
\hline Watching instructional videos & 87.13 \\
Browsing PPT & 86.83 \\
Reading other text materials & 81.9 \\
\hline
\end{tabular}

$92 \%$ of students believed course materials, videos, e-books and other learning materials provided by the teacher were helpful to them.

Table 6. Degree of help offered by videos, e-books and other learning materials provided by the teacher.

\begin{tabular}{lll}
\hline Items (Single Choice) & Subtotal & Ratio \\
\hline All materials & 43 & $19.63 \%$ \\
Most materials & 158 & $72.15 \%$ \\
Few materials & 18 & $8.22 \%$ \\
No materials & 0 & $0 \%$ \\
Total & 219 & \\
\hline
\end{tabular}

$57.53 \%$ of students stated that an unclear assessment method puzzled them during online learning. $47.95 \%$ considered academic pressure too high. $46.58 \%$ believed that learning resources were insufficient. $27.85 \%$ of students believed that network environment problems affected online learning. A small number of students believed that there were problems concerning teacher feedback (e.g., not timely, etc.).

Table 7. Difficulties/problems students have.

\begin{tabular}{|c|c|c|c|}
\hline Items (Multiple Choice) & Subtotal & Ratio & \\
\hline Do not have adequate network conditions at the time needed, cannot learn as planned & 61 & 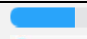 & $27.85 \%$ \\
\hline Inadequate teacher preparation & 10 & 4 & $4.57 \%$ \\
\hline Teacher Q \& A not timely & 11 & 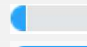 & $5.02 \%$ \\
\hline Lack of learning resources & 102 & & $46.58 \%$ \\
\hline Overwhelmed and unable to maintain learning progress & 105 & & $47.95 \%$ \\
\hline Unclear assessment method & 126 & & $57.53 \%$ \\
\hline Total & 219 & & \\
\hline
\end{tabular}




\section{Discussion}

The COVID-19 outbreak launched online teaching across the country for the first time in Chinese history. This new initiative has required education departments of all levels throughout the country work to their utmost to make online teaching as close to face-to-face teaching as possible [12]. In general, online teaching used in the department of Diagnostics is relatively orderly, which is attributed to careful organization by the Academic Affairs Office, challenging material prepared by clinical teachers, and the assistance of the domestic network communication department and the education department opening various, related educational resources for free [13].

According to the statistics, most students can access online courses on time, watch the instructional videos and complete the homework. The homework grades are also normally distributed. However, it is unclear whether students effectively watched the instructional videos, whether the homework was completed independently, how reliable the homework results were, and whether the homework results truly represented students' mastery. Therefore, the effect of online teaching still requires confirmation, using exams after the epidemic.

Table 1 shows that the vast majority of students use smart phones for classes, which is due to mobile phones' convenience and China's booming communications industry in recent years. However, because students generally take more than 10 other online courses on average and mobile phone screens are small, mobile phone learning may pose significant harm to students' eyesight [14]. Moreover, most teaching PPTs are bright and visually compelling so that they remain interesting, straining students' eyes further. Therefore, the college recommends that instructional video segments should be no more than 15 minutes long [15]. If students can take frequent breaks, they can relax their eyes and avoid visual fatigue. The college also issued additional eye hygiene guidelines to maximize student eye protection.

Table 2 shows that students spend 3-6 hours per week on the Diagnostics course, which is the same amount students spent before it was an offline course. Table 3 shows that most students can obtain the provided resources for online courses, indicating that network communication levels in the students' home regions have performed well. However, a small number of students can still only obtain few resources. Additionally, a few students listed in Table 7 believe that the internet environment affects learning, which we believe may be related to low level communication networks in less developed areas, such as Xinjiang and Tibet, which need improvement. Table 5 shows that the browsing fluency of instructional videos reached $87.13 \%$, which was unexpected. Because schools across the country now fully conduct online teaching, unimaginable pressure is on networks. Most course leaders worry about the fluency of the network more than they do about teaching online. So far, the ideal solutions may be related to colleges organizing student learning at different times and supporting the National Information Network Department.

Table 4 shows that teachers are helping students understand learning objectives and requirements, corresponding to the content through the Fanya. Chaoxing app, and Table 6 shows that students believe that the majority of teaching resources provided are beneficial to their learning. However, as seen in Table 7, students believe that the course assessment method was ambiguous, which caused confusion. Vague assessments are a significant problem. Teachers were confronted with this sudden teaching method, and they do not know when they can return to conventional teaching. In addition, the credibility of student grades for students who complete and assess homework at home cannot be verified. Moreover, many question whether it is fair to include homework grades in the overall course grade and how much of the final grade homework should be worth. Most courses cannot reformulate reasonable assessment methods that they can also publish for students in a short time period.

In the past, online teaching was used to supplement face-to-face courses, and homework was a relatively small portion of the work. Since online courses have now completely replaced face-to-face teaching, teachers have no experience with the sheer load of homework. The overburdened pressure on schoolwork shown in Table 7 may be related to the excessive amount of homework. Therefore, the Academic Affairs Office will later adjust the curriculum to weigh the amount and type of homework appropriately.

Since many teachers in the First Clinical Medical College are clinical doctors, a considerable number of teachers were dispatched to the epidemic's front lines. The remaining clinical teachers faced a significant shortage of manpower. Under the circumstances, both clinical and teaching, lesson preparation time was limited. Hence, the $46.58 \%$ of students who thought there were insufficient learning resources may be related to these causes. Therefore, it is particularly important to give attention to developing and retaining excellent teaching materials in the future to build up the curriculum itself and to cope with emergencies.

The epidemic started during the winter vacation, and as most students were already at home without a chance to go back to the school, they did not have textbooks. To support this need in national education, major domestic publishers have provided electronic textbooks for free for university use. Our college would like to thank the People's Medical Publishing House for sponsoring medical schools nationwide to use its electronic textbooks free of charge.

The worldwide outbreak of COVID-19 caught everyone off guard $[16,17]$. In education, online teaching has become the best way to respond [18, 19], it also provides an opportunity for students to learn independently [20]. This article introduces some of the advantages and disadvantages of online teaching under public health disasters. We hope this will be a guide for other institutions to refer to, and we would like to pay tribute to the heroes fighting the epidemic. 


\section{Conclusion}

All the students can study online with different kinds of digital devices. It takes students almost the same time studying as it before. Although most of the students believe they can obtain the useful materials online, lack of learning resources, overwhelmed and unable to maintain learning progress are the matters.

\section{References}

[1] Velavan TP, Meyer CG. (2020). The COVID-19 epidemic. Tropical medicine \& international health: TM \& IH, 25, 278-80.

[2] Sun P, Lu X, Xu C, Sun W, Pan B. (2020). Understanding of COVID-19 based on current evidence. Journal of Medical Virology.

[3] The Ministry of Education. (2020). Circular of the Ministry of Education of the people's Republic of China on the postponement of the opening of the spring semester 2020, http://www.moe.gov.cn/jyb_xwfb/gzdt_gzdt/s5987/202001/t2 0200127_416672. Html, 2020-01-27.

[4] The Ministry of Education. (2020). Ministry of Education: using Internet platform, "suspended class, ongoing learning." http://www.moe.gov.cn/jyb_xwfb/gzdt_gzdt/s5987/202001/t2 0200129_416993. Html, 2020-01-29.

[5] Nathwani D, Guise T, Gilchrist M. (2017). e-learning for global antimicrobial stewardship. The Lancet Infectious diseases, 17, 579 .

[6] Li X, Lei J. (2018). Discussion of the Application of Micro-lecture in the Clinical Training of Thoracic Surgery. Chinese journal of lung cancer, 21, 252-5.

[7] Heller RF. (2014). Learning by MOOC or by crook. The Medical journal of Australia, 200, 192-3.

[8] The Ministry of Education. (2019). The Ministry of education makes great efforts to build the "Golden College" and "Golden course".

http://www.moe.gov.cn/fbh/live/2019/50601/mtbd/201904/t20 190430_380194.html,2019-04-29.

[9] Macznik AK, Ribeiro DC, Baxter GD. (2015). Online technology use in physiotherapy teaching and learning: a systematic review of effectiveness and users' perceptions. BMC medical education, 15, 160.
[10] Xiang C, Zhibin H. (2020). Guidelines on COVID-19 Prevention and Control in Higher Education Institutes. Beijing. People's Medical Publishing House.

[11] The Ministry of Education. (2020). The Ministry of Education organized national college students together attend a live class on ideological and political related to epidemic prevention and control. 2020-03-07.

[12] Jiemodui. (2020). [Corporate donations]"suspend class, ongoing learning". https://www.jiemodui.com/N/113020.html? ft=detail\& fid=943 59, 2020-01-28.

[13] Jiaoli L, Xiaoqing Z, Xuanze C. (2020). Case Analysis of the Online Instruction in the Context of "Classes Suspended but Learning Continues" for Plague Prevention, China Educational Technology, 106-13.

[14] McKay FH, Cheng C, Wright A, Shill J, Stephens H, Uccellini M. (2018). Evaluating mobile phone applications for health behaviour change: A systematic review. Journal of telemedicine and telecare, 24, 22-30.

[15] Xu Y, Deng G, Wang W, Xiong S, Xu X. (2019). Correlation between handheld digital device use and asthenopia in Chinese college students: a Shanghai study. Acta ophthalmologica, 97, e442-e7.

[16] Sohrabi C, Alsafi Z, O'Neill N, Khan M, Kerwan A, Al-Jabir A, et al. (2020). World Health Organization declares global emergency: A review of the 2019 novel coronavirus (COVID-19). International journal of surgery (London, England), 76, 71-6.

[17] Habibzadeh P, Stoneman EK. (2020). the Novel Coronavirus: A Bird's Eye View. The international journal of occupational and environmental medicine, 11, 65-71.

[18] Skiba DJ. (2016). The State of Online Education. Nursing education perspectives, 37, 244-5.

[19] Huang JJ, He XJ, Bai WW. (2018). Application of lecture based learning plus problem based learning method in instruction of cardiac physical examination in clinical diagnostics (in Chinese). Chin Heart J, 30, 248-50.

[20] Dhaliwal N, Simpson F, Kim-Sing A. (2018). Self-paced online learning modules for pharmacy practice educators: Development and preliminary evaluation. Currents in pharmacy teaching \& learning, 10, 964-974. 